\title{
Temperature Effect to Altitude Corrections and Operational Application
}

\author{
Jan Cejnar ${ }^{1}$, Iveta Kameníková1*
}

${ }^{1}$ Czech Technical University in Prague, Faculty of Transportation Sciences, Prague, Czech Republic

*Corresponding author: Czech Technical University in Prague, Faculty of Transportation Sciences, Horská 3, 12801 Prague, Czech Republic, E-mail: kamenive@fd.cvut.cz

\section{Abstract}

The article is focused to familiarize the reader with air mass behaviour, legislative requirements and methods of altitude corrections. The goal of the article is evaluation of the presently used operational procedures applied to the altitude corrections according to the change of air parameters. The final part of the article determines altitudes necessary for corrections and represents the proposal of optimized altitude correction method.

\section{Keywords}

Legislation, Minimum Altitudes, Altitude Correction, Temperature Impact, Air Mass

\section{Introduction}

The application of altitude corrections has not been applied through the whole aviation world for years. It has been an exception of several air carriers. However, the change of the attitude to this issue can be seen in last decade. The example of the new trend is improvement of awareness connected with discussed topic as well as the introduction of materials to different groups participating on the air transport. The example is represented by publication „Guidelines for Cold Temperature Corrections" issued by Eurocontrol in 2014. Although, altitude corrections have mainly seasonal or regional matter, it is necessary to keep them in mind during everyday operations. The corrections do not have significant effect to high number of flights. On the other hand, it may immediately endanger the safety of the flight in extreme weather conditions. [1]

The thesis is focused to description of altitudes requiring corrections and gives the explanation of the practical importance of these altitudes in operations. Another section compares different methods of corrections dependent on the temperature changes according to the legislation. The results are evaluated and based on practical use in air operations.

Partial goal of the thesis is evaluation of currently used altitude correction methods of selected air carriers. The main goal is the proposal of optimized altitude correction method as well as the definition of altitudes where the corrections are necessary for the safety of the flight.

\section{Theory and Methods}

At the beginning of the thesis are summarized theoretical basis necessary for understanding of the altitude corrections problem. First is described behaviour of the air mass dependent on the change of air temperature or pressure. For complex understanding there is a need for the basic knowledge of the principle of barometric altimeter including its setting and indication dependent on specific setting. Important part is focused to legislative requirements connected with altitude corrections. 
These requirements are described and divided for air carriers, commanders and ATC officers.

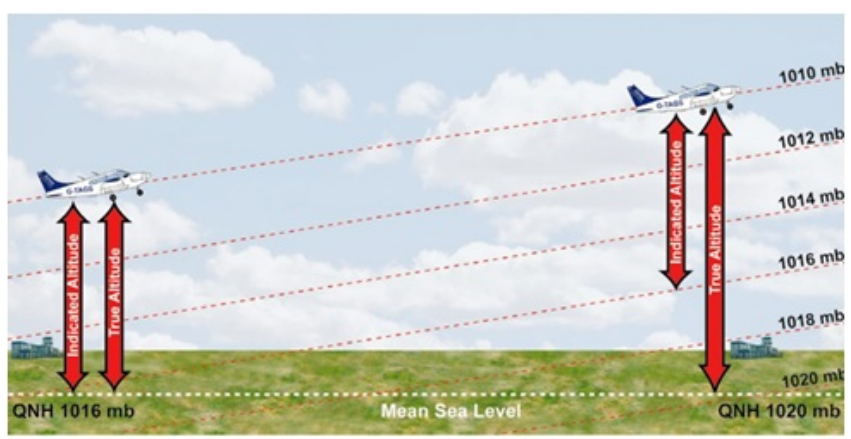

Figure 1. Graphical visualization of air mass behaviour with pressure change [2]

\subsection{Analysis of procedures applied in operation}

Following section is focused to anonym survey through air carriers in Europe. It compares operational application of altitude correction methods in commercial air transport. The analysis of operational manuals shows the applied methods by flight crews and enables the comparison with legislative requirements. Survey is focused to specific data about airline as the state of AOC registration, prevailing type of operation, corrected altitudes, impact of temperature, impact of pressure and impact of wind. The outcome of analysis is considered during the preparation of final proposal of optimum altitude correction method.

\subsection{Air column behaviour caused by the change of air density}

The primary presumption of understanding to altitude corrections is the air mass behaviour knowledge dependent on the change of air temperature and pressure. It can be wondered as a change of air density in the virtual air column.

That means:

- density is directly proportional to air pressure - the air column is reduced with increasing pressure therefore, density is increased and vice versa.

- density is inversely proportional to air temperature the air column is extended with increasing temperature therefore, density is decreased and vice versa.

- density is inversely proportional to air humidity - humidity represents the content of water vapour in the air. Humid air is lighter due to high concentration of $\mathrm{H}_{2} \mathrm{O}$ molecules, which are lighter than $\mathrm{N}_{2}$ and $\mathrm{O}_{2}$ molecules.

The relations described in the article above represent the elemental principle for calculations of true and indicated altitude or height. The Table 1 is a simplification of these rules for calculations from indicated altitude to true altitude and vice versa.
Temperature in the Table 1 is compared with the ISA conditions and its standard drop with increasing altitude, namely $2{ }^{\circ} \mathrm{C} / 1000 \mathrm{ft}$. It means the words "higher" and "lower" represent the difference of ambient air temperature from the ISA. Pressure is compared with value $1013,25 \mathrm{hPa}$ as defined in the ISA model. The pressure difference may also exist when flight crew accidentally set incorrect setting on altimeter. Then it can be compared as a difference between true air pressure and incorrect pressure setting. [2]

\subsection{Example of pressure change impact}

Examples of pressure and temperature impact to altitude change are described as a part of theoretical section. These examples are simple calculations applicable in operations. They are also included in the ATPL theoretical exams. The example below shows the solution of these types of calculations as well as it gives aid how to work with Table 1. Altitude correction dependent on pressure change example - Figure 1. [2]

- Indicated altitude: $3000 \mathrm{ft}$

- $\mathrm{QNH}_{1}: 1016 \mathrm{hPa}$

- $\mathrm{QNH}_{2}: 1020 \mathrm{hPa}$

$$
\begin{gathered}
Q N H_{2}-Q N H_{1}=\Delta Q N H \\
1020-1016=4 h P a \\
\Delta Q N H * 30 f t=\Delta h \\
4 * 30=120 f t \\
h_{\text {indicated }}+\Delta h=h_{\text {true }} \\
3000+120=3120 f t
\end{gathered}
$$

\subsection{Example of temperature change impact}

The example solved below shows the calculation of altitude correction with change of air temperature. The flight represented on Figure 2 is performed from high temperature region to the area of low temperature. These two regions are compared between each other to demonstrate temperature effect. For practical purposes the comparison with ISA temperature should be applied. The consequence is difference between initial and final true altitude. [2]

- $\mathrm{QNH}_{1}: 1020 \mathrm{hPa}$

- $\mathrm{QNH}_{2}: 1020 \mathrm{hPa}$

- $\mathrm{t} 1: 30^{\circ} \mathrm{C}$

- t2: $-10{ }^{\circ} \mathrm{C}$

- Indicated altitude: $3000 \mathrm{ft}$

- $4 \%$ altitude change per $10{ }^{\circ} \mathrm{C}$ deviation from ISA

- True altitude=? 
Table 1. Altitude calculations

\begin{tabular}{|l|l|l|l|}
\hline Altitude (height) & Temperature & Pressure & Altitude change \\
\hline \multirow{2}{*}{ Indicated $\gg$ True } & higher & higher & add \\
\cline { 2 - 4 } & lower & lower & subtract \\
\hline \multirow{2}{*}{ True $\gg$ Indicated } & higher & higher & subtract \\
\cline { 2 - 4 } & lower & lower & add \\
\hline
\end{tabular}

$$
\begin{gathered}
t_{2}-t_{1}=\Delta t \\
-10-30=-40^{\circ} \mathrm{C} \approx 16 \% \\
\frac{h * 16 \%}{100 \%}=\Delta h \\
\frac{3000 * 16 \%}{100 \%}=480 \mathrm{ft}
\end{gathered}
$$

When the air temperature in Point 2 is lower than temperature in Point 1, then the true altitude is lower according to Table 1.

$$
\begin{aligned}
& h_{\text {indicated }}+\Delta h=h_{\text {true }} \\
& 3000-480=2520 f t
\end{aligned}
$$

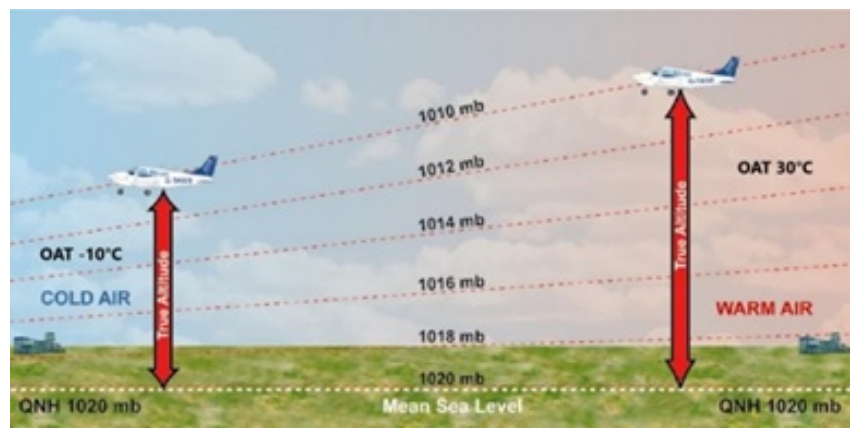

Figure 2. Graphical visualization of air mass behaviour with temperature change (modified by author) [2]

\subsection{Altitude correction method}

The proposal of optimum method considers legislative requirements as well as recommended methods for low temperature altitude corrections by Doc8168. The consequence rising from Doc8168 are operational limitations for specific methods that must be considered as well. The results of the survey through operational manuals of selected carriers are included too. Whole selection process and proposal is focused to maintain the applied method highly practicable and simple as much as possible. Recommended method:

- $4 \%$ altitude change per $10{ }^{\circ} \mathrm{C}$ deviation from ISA for temperatures up to $-15^{\circ} \mathrm{C}$

- Table on figure 3 for temperatures below $-15^{\circ} \mathrm{C}$
Recommended method considers temperature limitation below $-15{ }^{\circ} \mathrm{C}$ for simple $4 \%$ correction method according to Doc8168. On the other hand, this method ensures higher accuracy than the Table on figure 3, due to that fact it may be useful in limiting conditions. Important fact is that one of this combined method or recommended combination is familiar for $87 \%$ of air carriers participating on the survey. It reduces requirements for additional flight crew training, and they can apply this method in operations. This recommendation does not change the role of the commander and his decision for adequate altitude correction according to specific conditions. The purpose of this method let the flight crew calculate corrections with higher accuracy, which may help them in limiting weather conditions to reach and maintain prescribed altitude. $[3,4,5]$

\subsection{Corrected altitude proposal}

Altitudes requiring corrections result from legislative requirements Doc8168 and Doc4444 as well as from operational manuals of air carriers participating in the survey. These altitudes can be divided to 2 groups according to their operational purpose.

First group consists of minimum altitudes. These altitudes primary provide obstacle clearance. They are mainly intended for non-standard and emergency situations.

- MOCA (minimum obstruction clearance altitude)

- MORA (minimum off-route altitude)

- Grid MORA (grid minimum off-route altitude)

- MEA (minimum enroute altitude)

- MSA (minimum sector altitude)

Second group contains altitudes defined as a part of departure, arrival, approach and missed approach procedure. All these altitudes requiring corrections dependent on the air parameters change according to the relations and methods previously shown, when applicable on specific procedure. Altitudes existing on the final approach and its corrections are not clear for high number of pilots, so this section is focused to them. Tables on Figure 4 and Figure 5 are shown below to divide the final stage with respect to used type of approach system. Requirements for corrections are graphically represented for specific altitudes, when applicable to the approach procedure. [5, 6] 


\begin{tabular}{|c|c|c|c|c|c|c|c|c|c|c|c|c|c|c|}
\hline \multirow{2}{*}{$\begin{array}{c}\text { Aerodrome } \\
\text { temperature } \\
\left({ }^{\circ} \mathrm{C}\right)\end{array}$} & \multicolumn{14}{|c|}{ Height above the elenution of the altimeter setting source (feet) } \\
\hline & 200 & 300 & 400 & 500 & 600 & 700 & 800 & 900 & 1000 & 1500 & 2000 & 3000 & 4000 & 5000 \\
\hline 0 & 20 & 20 & 30 & 30 & 40 & 40 & 50 & 50 & 60 & 90 & 120 & 170 & 230 & 280 \\
\hline-10 & 20 & 30 & 40 & 50 & 60 & 70 & 80 & 90 & 100 & 150 & 200 & 290 & 390 & 490 \\
\hline-20 & 30 & 50 & 60 & 70 & 90 & 100 & 120 & 130 & 140 & 210 & 280 & 420 & 570 & 710 \\
\hline-30 & 40 & 60 & 80 & 100 & 120 & 140 & 150 & 170 & 190 & 280 & 380 & 570 & 760 & 950 \\
\hline-40 & 50 & 80 & 100 & 120 & 150 & 170 & 190 & 220 & 240 & 360 & 480 & 720 & 970 & 1210 \\
\hline-50 & 60 & 90 & 120 & 150 & 180 & 210 & 240 & 270 & 300 & 450 & 590 & 890 & 1190 & 1500 \\
\hline
\end{tabular}

Figure 3. Altitude corrections dependent on temperature

\begin{tabular}{|c|c|c|c|c|c|c|}
\hline Type of Approach & NDB & NDB/DME & VOR & VOR/DME & ILS & MLS \\
\hline MSA & $\checkmark$ & $\checkmark$ & $\checkmark$ & $\checkmark$ & $\checkmark$ & $\checkmark$ \\
\hline Procedure altitude & $\checkmark$ & $\checkmark$ & $\checkmark$ & $\checkmark$ & $\checkmark$ & $\checkmark$ \\
\hline Reversal/racetrack & $\checkmark$ & $\checkmark$ & $\checkmark$ & $\checkmark$ & $\checkmark$ & $\checkmark$ \\
\hline FAF & & $\checkmark$ & & $\checkmark$ & & \\
\hline FAP & & & & & $\checkmark$ & $\checkmark$ \\
\hline Step-down fix & $\checkmark$ & $\checkmark$ & $\checkmark$ & $\checkmark$ & & \\
\hline Approach path* & & $\checkmark$ & & $\checkmark$ & & \\
\hline Glide slope check & & & & & $\checkmark$ & \\
\hline MDA/H & $\checkmark$ & $\checkmark$ & $\checkmark$ & $\checkmark$ & & \\
\hline DA/H & & & & & $\checkmark$ & $\checkmark$ \\
\hline Missed approach* & $\checkmark$ & $\checkmark$ & $\checkmark$ & $\checkmark$ & $\checkmark$ & $\checkmark$ \\
\hline
\end{tabular}

Figure 4. Conventional approach corrected altitudes

\section{Discussion}

The thesis results meet the legislative requirements and show possible operational applications of altitude corrections methods. The goal of the thesis is to increase the flight crew awareness as well as improve understanding of discussed problem. However, there should not be any tendency to increase flight crew workload in operations by complicated calculations and assumptions. It may lead to reduction of mental capacity necessary for another crew activity.

\section{Conclusion}

Altitude corrections dependent on the air pressure and temperature are based on the air mass behaviour theory. This theory is used for further assumptions and altitude calculations in the thesis. The regulations are divided and stressed to each participant of air transport as operators, commanders and ATC officers. Theoretical section of the thesis is extended by automatic altitude correction systems, which have high potential for further growth in the future.

First section of practical part is focused to air carriers survey in the Europe. Information from operational manuals are used to rise the knowledge of present operational methods. The results are applied on theoretical basis to obtain combination of practical and theoretical requirements.

Although, the Doc8168 gives precise aid how to calculate the altitude corrections, there is a short article about altitudes requiring corrections with general statement only. That is the

\begin{tabular}{|c|c|c|c|c|c|}
\hline Type of Approach & LNAV & LNAV/VNAV & LPV & LP & GLS \\
\hline MSA & $\checkmark$ & $\checkmark$ & $\checkmark$ & $\checkmark$ & $\checkmark$ \\
\hline Procedure altitude & $\checkmark$ & $\checkmark$ & $\checkmark$ & $\checkmark$ & $\checkmark$ \\
\hline Reversal/racetrack & $\checkmark$ & $\checkmark$ & $\checkmark$ & $\checkmark$ & $\checkmark$ \\
\hline FAF & $\checkmark$ & & & $\checkmark$ & \\
\hline FAP & & $\checkmark$ & $\checkmark$ & & $\checkmark$ \\
\hline Step-down fix & $\checkmark$ & & & $\checkmark$ & \\
\hline Approach path* & $\checkmark$ & & & $\checkmark$ & \\
\hline Glide slope check & & & & & \\
\hline MDA/H & $\checkmark$ & & & $\checkmark$ & \\
\hline DA/H & & $\checkmark$ & $\checkmark$ & & $\checkmark$ \\
\hline Missed approach** & $\checkmark$ & $\checkmark$ & $\checkmark$ & $\checkmark$ & $\checkmark$ \\
\hline
\end{tabular}

Figure 5. RNAV approach corrected altitudes

*term Approach path represents discrete altitudes of 2D approach

**term Missed approach represents all altitudes published in Missed approach procedure

reason why extensive part of thesis is focused to definition of corrected altitudes. The proposal of altitudes is created with respect to operational limitations such as obstacle clearance, airspace profile, traffic separation, radionavigational minima, communication and surveillance coverage. This topic could be extended by proposal of automatic altitude correction systems working on principle with respect to the terrain profile and meteorological conditions, which are not applied to manual methods such as temperature inversion.

\section{References}

[1] Eurocontrol guidelines for cold temperature corrections by ats. Oct 2014. URL https: //www.eurocontrol.int/publication/ eurocontrol-guidelines-coldtemperature-corrections-ats.

[2] ATPL Ground Training Series: Meteorology. CAE OXFORD AVIATION ACADEMY, Shoreham, England, 4 edition, 2008.

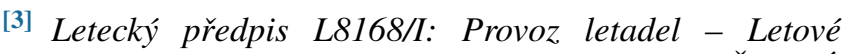
postupy. MINISTERSTVO DOPRAVY ČESKÉ REPUBLIKY, 2019. URL https://aim.rlp. 
cz/predpisy/predpisy/dokumenty/L/L8168i/data/print/L-8168-I_cely.pdf.

[4] Letecký předpis L8168/III: Provoz letadel Provozní postupy letadel. MINISTERSTVO DOPRAVY ČESKÉ REPUBLIKY, 2019. URL https://aim.rlp.cz/predpisy/predpisy/ dokumenty/L/L-8168iii/data/print/L8168-III_cely.pdf.

[5] Doc 8168 - Procedures for Air Navigation Services: Aircraft Operations. ICAO, 5 edition, 2006. URL https://www.bazl.admin.ch/dam/bazl/ de/dokumente/Fachleute/Flugplaetze/ ICAO/icao_doc_8168_aircraftoperations. pdf.download.pdf/icao_doc_8168_ aircraftoperations.pdf.

[6] General Airway Manual. Englewood. JEPPESEN, 2014. 